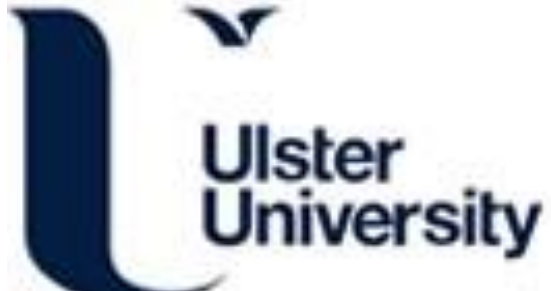

\section{Structural and surface modification of carbon nanotubes for enhanced hydrogen storage density}

Rajaura, R. S., Srivastava, S., Sharma, P. K., Mathur, S., Shrivastava, R., Sharma, S. S., \& Vijay, Y. K. (2018). Structural and surface modification of carbon nanotubes for enhanced hydrogen storage density. NanoStructures and Nano-Objects, 14, 57-65. https://doi.org/10.1016/j.nanoso.2018.01.005

Link to publication record in Ulster University Research Portal

\section{Published in:}

Nano-Structures and Nano-Objects

Publication Status:

Published (in print/issue): 01/04/2018

DOI:

10.1016/j.nanoso.2018.01.005

\section{Document Version}

Author Accepted version

\section{General rights}

Copyright for the publications made accessible via Ulster University's Research Portal is retained by the author(s) and / or other copyright owners and it is a condition of accessing these publications that users recognise and abide by the legal requirements associated with these rights.

\section{Take down policy}

The Research Portal is Ulster University's institutional repository that provides access to Ulster's research outputs. Every effort has been made to ensure that content in the Research Portal does not infringe any person's rights, or applicable UK laws. If you discover content in the Research Portal that you believe breaches copyright or violates any law, please contact pure-support@ulster.ac.uk. 


\title{
Structural and Surface Modification of Carbon Nanotubes for Enhanced Hydrogen Storage Density
}

\author{
Rajveer Singh Rajaura ${ }^{1, *}$, Subodh Srivastava ${ }^{1, *}$, Preetam Kumar Sharma², Shubhra Mathur ${ }^{2}$, \\ Rupali Shrivastava ${ }^{3}$, S. S Sharma ${ }^{4}$ and Y.K. Vijay ${ }^{1}$ \\ ${ }^{1}$ Department of Physics, Vivekananda Global University, Jaipur -303012, India \\ ${ }^{2}$ Department of Physics, University of Rajasthan, Jaipur- 302004, India \\ ${ }^{3}$ Department of Chemistry, Vivekananda Global University, Jaipur -303012, India \\ ${ }^{4}$ Department of Physics, Govt. Women Engineering College, Ajmer-305002, India
}

\begin{abstract}
In this paper, we report the synthesis of functionalized carbon nanotubes (F-CNTs) by acid treatment and their hydrogen storage properties. These F-CNTs have been characterized by XRD, FTIR, Raman spectroscopy and electron microscopy techniques. The results show that the structure and morphology of P-CNTs have been modified after the acid treatment. The hydrogen storage capacity was determined by volumetric measurements at room temperature and experimental results showed that the storage capacities of P-CNTs and F-CNTs were $0.65 \mathrm{wt} \%$ and $0.89 \mathrm{wt} \%$, respectively. A notable enhancement in hydrogen storage capacity of F-CNTs was observed which could be attributed to the enhanced oxygen functionalities, opening of end caps and presence of surface defects that offered enhanced surface area for hydrogen adsorption. The key results of present research show that structural, morphological and chemical changes are responsible factors to enhance the hydrogen storage density.
\end{abstract}

Keywords:Hydrogen storage, functionalized carbon nanotubes, chemical functionalization, adsorption, Raman spectroscopy.

Corresponding Author: Email: rajveer.nano_cct@live.com (R. S. Rajaura), subodhphy@gmail.com (Subodh Srivastava) 


\section{Introduction}

The ever-increasing worldwide demand of energy consumption, as well as concern about shortage of non-renewable fossil fuels (petroleum, coal, oil and gas) and global warming has inspired scientific community to do intensive research to develop new alternative sustainable energy sources that can replace carbon based fossil fuels [1]. There are number of alternative energy sources such as solar, wind, ocean, geothermal and hydrogen [2]. Hydrogen is one of the potential green fuels because it is lightweight, eco-friendly, renewable, and four times more efficient than petroleum [3-4]. For the utilization of molecular hydrogen as energy carrier, its production, storage and transportation crucial. Hydrogen storage is one of the major challenges because hydrogen is present in the gaseous form in ambient condition. Hydrogen is the lightest gas in the atmosphere. Hydrogen gas can be stored as (i) pressurized gas, (ii) cryogenic liquid, (iii) solid fuel as chemical (metal hydrate) or physical combination (carbon material) [5]. All the storage methods are discussed in the following reviews [6-7]. The cryogenic hydrogen storage requires cryogenic unit to maintain the temperature that makes it an energy consuming process. The high pressure hydrogen storage requires high pressure and high mechanical strength piston pump. Although each of above storage methods have some advantages but none of them satisfy the size, efficiency, weight, and safety necessities for own transportation vehicle [8]. Solid fuel by means of physical combination in which hydrogen is physically bonded to the surface of potential materials is another alternative for hydrogen storage.

Carbon is one of the adsorbent for gases because these materials demonstrate unusual properties with highly spongy structure and the existence of specific interfaces among the carbon atoms and hydrogen gas [9-11]. The properties of carbon such as high mechanical strength, long life, efficient heat transfer coefficient, fast thermodynamically kinetics (quick uptake and release) 
make it a desirable material for hydrogen storage. In addition, carbon materials have the advantage of being lighter than the inorganic compounds that are available in the market [12-14]. In 1991, Iijima et al. added a new member of carbon family, namely carbon nanotubes that have the ability of high hydrogen storage density [15]. The variety of carbon nanostructured materials, such as multi walled carbon nanotubes [10], single walled carbon nanotubes [11], graphene based derivative [14] and other varies carbon [13] materials have been investigated experimentally as well as theoretically for various energy applications including hydrogen storage. For instance, ammonia boranes have received significant attention in recent years as a source of hydrogen [16]. Sen et al. have extensively investigated various carbon nanocomposite materials for hydrogen generation from ammonia boranes [17-20]. The novel carbon nanomaterials namely CNT, graphene and graphene oxidewere mixed with metallic and metallicalloy nanomaterials to prepare thenanocomposites [21, 22]. Ruthenium-cobalt alloy nanoparticles-functionalized MWCNTs (RuCo-FMWCNT) composites have been demonstrated to be the best catalyst for the dehydrogenation of dimethylamine borane (100\% conversion, turn over frequency $\left.775.28 \mathrm{~h}^{-1}\right)$ [23]. Carbonmetal composites have also been explored for other application including solar cell and organic synthesis $[\mathbf{2 4}, \mathbf{2 5}]$. Darkrim and Wang groups using computational methods proposed that the hydrogen molecules are absorbed by the carbon structure due to the Van der Waal's force on the surface of the material $[26,27]$. Cheng et al. reported that storage capacity of carbon nanotube increases by the optimization of CNT diameter, inter-tube spacing and array configuration. They demonstrated that single walled carbon nanotubes can store more than 10.0 wt.\% hydrogen at $298 \mathrm{~K}$ and $10 \mathrm{MPa}$ [28]. Carbon nanotube is one of the most interesting material due to their structural characteristics, such as high theoretical surface area, porosity, 
high mechanical strength and durability, effective heat transfer, narrow pore size distribution and low mass density [29]. Durgun et al. studied the hydrogen storage capacity theoretically using first principle method and showed transition metals decorated carbon nanotube may bind multiple $\mathrm{H}_{2}$ molecules which could be correlated with enhanced hydrogen storage capacity [30]. Zuttle et al. Experimentally investigated the hydrogen absorption through the surface of carbon nanotubes [31]. Hydrogen storage study has been carried out for CNT at $10.5 \mathrm{MP}$ pressure is 0.7 wt.\% [32] and in CNT film is $8 \mathrm{wt} . \%$ [33] at room temperature and ambient pressure. Recently, Reddy et al. [34] reported the platinum dispersion on single walled carbon nanotubes enhances the storage capacity. Gayathri et.al. have been studied the $\mathrm{H}_{2}$ adsorption in defected CNTs and reported that hydrogen can be adsorbed on carbon nanotube in two manners physical adsorption and chemisorption [35]. Interconnected carbon nanotubes (CNT) composed a newly diamondlike architecture namely super diamond. It has been designed by tunable pores and controlling the location of defects. The hydrogen storage properties were studied thoroughly via ab-initio and Grand Canonical Monte Carlo simulations and results showed the gravimetric capacity of $20 \%$ at $77 \mathrm{~K}$ and can reach the high value of $8 \%$ at room temperature [36]. Sharma et al. Showed a comparative study of hydrogen storage capacity of GO and Go-PANI nanocomposite and reported the GO-PANI nanocomposite has low storage capacity in comparison to GO [37]. Interlayer spacing, functional group and defect density also play a major for enhance the hydrogen storage density $[38,28]$.

Yildrim etal.studied the hydrogen storage capacity theoretically and predict the functionalized the carbon nanotube with $\mathrm{Sc}, \mathrm{V}$ and $\mathrm{Ti}$ holds high theoretical gravimetric densities of $9.8,9.2$ and $7.8 \mathrm{wt} \%$ respectively [39]. However, Liu et al. reported the 2.9wt.\% hydrogen storage capacity of hybrid GO-MWCNTs nanocomposites[40]. Ruoff 
etal.synthesized the graphene like nanosheets reduction of exfoliated graphite and studied the hydrogen storage behavior [41]. Similarly, Kim et al. thermally reduced the graphene oxide, note the hydrogen storage capacity, and explore the functional group play a major role to enhance the hydrogen storage [42]. Rao et. al study the effect of acid treatment of CNTs and their hydrogen storage behavior [43]. Cheng et al. activated CNT via various chemical and physical techniques and report the opening the defective siteand surface modification after activation a major way to enhance the modified carbon nanotubes [44]. Nanostructure graphite was prepared by mechanical milling under hydrogen atmosphere and the hydrogen storage performance was recorded [45]. A high hydrogen storage capacity of graphene, nitrogen-doped graphene and Pd decorated nitrogen-doped hydrogen exfoliated graphene nanocomposite is demonstrated under moderate temperature and pressure conditions [46]. High-pressure hydrogen sorption isotherms were investigated on by thermally reduced GP (TR-GO), chemically reduced GO (CR-GO) and graphene sheets decorated with Fe nanoclusters (Fe-GS) [47]. Li and K doped CNTs can hold $20 \mathrm{wt} \%$ and $14 \mathrm{wt} \%$ hydrogen at moderate or room temperatures, respectively, under ambient pressure [48].The high hydrogen-uptake capacity of these systems may be derived from the special open-edged, layered structure of the carbon nanotubes and used carbon precursor source and catalysis. G. E. Froudakis et al. investigate the hydrogen storage capacity in silicon -carbon nanotube using $\mathrm{Ab}$ initio simulation and report the hydrogen storsge capacity $3.6 \mathrm{wt} \%$ at high pressure [49]. M. Rodriguez et al synthesis the graphite nanofiber by dissociation of carbon containing gas on metal surface and synthesis the graphite nanofiber and report the hydrogen storage behavior [50]. The earlier 
reported hydrogen uptake capacity and some related parameters of carbon nanostructures have been summarized in table 1.

Many reports stated above used more than one-step for the activation of CNTs for hydrogen storage. Aiming towards simple activation procedure for CNTs, current research focus on enhancing the hydrogen storage density economically in graphene based derivatives. The activation can be achieved from different chemical and physical techniques, which results in increasing porosity, active sites, interlayer spacing and defects in the structure [51-52]. CNTs activation by acid treatment for hydrogen storage is a relatively a new approach with limited studies. In this paper, we are reporting, simple modification of P-CNTs using the chemical oxidation method and investigated the hydrogen storage properties.

\section{Experimental section}

\subsection{Synthesis of F-CNTs}

The P-CNTs were purchased from the Redux Private Ltd. India. The P-CNTs were 10-30 $\mu \mathrm{m}$ long with outside diameter 2-30 nm having purity level 95\%. Concentrated sulfuric acid $\left(\mathrm{H}_{2} \mathrm{SO}_{4}\right)$ and nitric acid $\left(\mathrm{HNO}_{3}\right)$ were purchased from Sigma-Aldrich. The CNTs were functionalized by the well-known chemical oxidation method [53-54]. In brief, a molar ratio of $3: 1 \mathrm{H}_{2} \mathrm{SO}_{4}$ and $\mathrm{HNO}_{3}$ solution was added to P-CNTs powder under ultra-sonication for $2 \mathrm{~h}$. The resultant solution was stirred at temperature $80^{\circ} \mathrm{C}$ for $24 \mathrm{~h}$. The solution was dried in vacuum oven followed by centrifugation at $4000 \mathrm{rpm}$ and the resultant pellet was collected. The overall synthesis procedure of F-CNTs is shown in figure 1. 


\subsection{Characterization techniques}

Transmission electron microscope (TEM, Tecnai G20 S-TWIN) was carried out $200 \mathrm{kV}$ bias. Scanning electron microscope (SEM) analysis was then carried out using Carl Zeiss EVO 18 at $20 \mathrm{kV}$ operating voltage. The X-ray diffractogram (XRD) was recorded using PanalyticalX'pert PRO MPD system using $\mathrm{Cu} \mathrm{K}_{\alpha}$ X-ray source. Raman spectra were recorded on the R-3000 Raman Systems with $514.5 \mathrm{~nm}$ Ar laser source. FTIR spectra were recorded using Shimadzu IR Affinity-1 FTIR spectrometer.

\subsection{Hydrogen storage Setup}

The hydrogen storage properties of the samples were investigated in a custom build hydrogen storage setup at room temperature as shown in figure 2 . The known amount of the materials was kept in the stainless-steel chamber and the setup was completely degassed for 30 minutes using rotary vacuum before any measurements. In the next step, particular pressures (for instance 80 bar) of ultra-pure hydrogen were introduced followed by the measurements of pressure drop with time. The measurements were repeated six times and average values have been reported in the paper [55].

\section{Results and discussions}

\subsection{Morphology}

The surface morphology of P-CNTs and F-CNTs were determined by SEM. Figure 3(a) shows the SEM image of agglomerated rough 3D structure of P-CNTs with intricate network of interconnected fiber-like structures. The acid treatment prevented the bundling and agglomeration of CNT fibers. As shown in figure 3(b), F-CNTs have increased intermediate 
spaces and groove openings. For further structural evidences, TEM analysis was performed for CNTs before and after of acid treatment [56].

Bright filed TEM image of P-CNTs figure 4(a) exhibits an inhomogeneous complex network of interconnected ropes like structure. This snowflake type uneven structure is usually good material for hydrogen storage [57]. But P-CNTs are not so capable of storing hydrogen enormously when compared to the functionalized forms of CNTs. The Low storage density of hydrogen in P-CNTs is due to the deficiency of oxygen functionalities and defect free surface that obstruct or abandon the adsorption of hydrogen on the surface of the P-CNTs. Therefore, functionalization overcomes the stated difficulties and helps in increased hydrogen efficiency. In this study, F-CNTs are synthesis after acid treatment and the TEM image of F-CNTs are shown in figure 4(b-f). The image 4(b) are showing a tree branch like structure aligned together which reveal comparatively rough surface for hydrogen storage after the functionalization. It also demonstrates the outside wall of the tube has been damage (black arrow line) through the oxidization of CNTs. This evidence is a direct proof of surface modification where we can observe the newly created defects in F-CNTs after oxidative treatment. The closer investigation in figure 4(c) shows the opening end cap of F-CNTs after chemical oxidation. This may attribute to additional attachment of oxygen functionalities and improves the storage efficiency of FCNTs. Figure 4 (d) shows that defect on surface of CNTs that specify the white circle area which had introduced the hydrogen friendly active sites on surface of F-CNTs. The high-resolution image in figure $4(\mathrm{e}-\mathrm{f})$ of shows the exact minuscule structure CNTs before and after of chemical oxidation. The darker line that is marked by white arrow line, which might be edge of graphene sheet are clearly visible in figure 4(e). This lattice fringe displaying interatomic interlayer spacing of F-CNTs is $0.34 \mathrm{~nm}$. After the chemical oxidation of P-CNTs, edge of graphene layer 
is partially destroyed, not well arranged, and poor crystalline with destructive surface morphology were also observed in figure 4(f). Similarly, result has been reported $[58,59]$ that chemical and physically modified could cause the defect on surface of CNTs.

\subsection{X-ray diffraction analysis}

The crystalline structure of P-CNTs and F-CNTs were studied by X-Ray diffraction shown in the figure 5. X-ray diffraction (XRD) has proved a useful tool to characterize the crystal structures and atomic spacing of CNTs. The high intensity peaks in XRD pattern of P-CNTs, black line, appear at angle of $25.7^{0}(002)$ conforming the interlayer distance $0.34 \mathrm{~nm}$ to significantly good nanotubes orientation [60]. The peaks at about $43^{\circ}$ and $53^{\circ}$ are due to $C(100)$ and $\mathrm{C}(004)$, respectively. The other peaks are believed to be due to the contamination. It is a simple approach to analysis the alignment of P-CNTs without destructing with their original alignment. The most intense peak of F-CNTs, red line, sheets appear at $2 \theta$ of $25.5 \square$ corresponding to the interlayer spacing $0.35 \mathrm{~nm}$. This facilitates to attachment of oxygen functional groups via strong acid treatment, which confirms the disturbance in the alignment of carbon nanotubes and increase in the inter-layer distance in between the graphene layers that is new propitious for enhance hydrogen storage density [61]. This result is further confirmed by the Raman spectroscopy measurements.

\subsection{Spectroscopic analysis}

Raman spectroscopy is highly sensitive to analysis the electronic structure of carbon nanostructure materials. It is important technique to analysis the single, double and multi wall of 
carbon nanotube. The Raman spectra of the P-CNTs and F-CNTs are shown in figure 6. The PCNTs show the three prominated peaks are located at 1325,1580 and $2644 \mathrm{~cm}^{-1}$ are shifted to FCNTs at $1347,1599,2683 \mathrm{~cm}^{-1}[62,63]$. The first peak is known as the D band, which is originated due to breathing mode of $\mathrm{sp}^{2}$-hybridization, and disorder structure in CNTs. The intensity of the D band is directly relative to the amount of defects in the sample. Second peak is called the $\mathrm{G}$ band, which is appearing due to in-plane vibration of $\mathrm{sp}^{2}$ carbon atoms and it is common for all $\mathrm{sp}^{2}$ carbon systems. Third peak is known as $2 \mathrm{D}$ band (historically know as G' band) that is originates from a process where two phonons with opposite momentum exchange occurs and it is overture of $\mathrm{D}$ band. The position and shape of $2 \mathrm{D}$ band is highly sensitive to determine the thickness and number of layer of graphitic materials. However, in process of FCNTs, the density of defect has been influence by acid treatment, that's via intensity of the 2D band decrease that is good agreements of previous publishing results [64, 65]. Further, the measuring the intensity ratio of $\mathrm{D}$ band and $\mathrm{G}$ band, we can get of information of disorder of FCNTs. As shown in the figure P-CNTs have the intensity ratio $\left(\mathrm{I}_{\mathrm{D}} / \mathrm{I}_{\mathrm{G}}\right)$ of 0.284 and after acid treatment F-CNTs show the higher intensity ratio of 0.433 . The high intensity ratio of F-CNTs can be attributed to the activate the various defective cavities and defect on the graphene edge along the tube as well as attachment functional group on F-CNTs surface; this outcome is consistent with our TEM observation. Finally, Raman spectra show the acid treatment looks to more effective in creation of defect on surface which leads to enrich the storage density in F-CNTs.

The FTIR spectroscopy was used to confirm the functional group finding process in the sample. Specific functionalities of carbonyl and hydroxyl groups should be present in the product. Figure 7 illustrates the FTIR spectra of P-CNTs and F-CNTs. The broad peaks at $3414 \mathrm{~cm}^{-1}$ and small 
peak $1333 \mathrm{~cm}^{-1}$ were observed for F-CNTs, it was attributed to the symmetric and asymmetric vibrations of $-\mathrm{OH}$, indicating the acid treatment has successfully occurred on CNTs. The another peaks of oxygen functionalities located at $1090 \mathrm{~cm}^{-1}$ and $1632 \mathrm{~cm}^{-1}$ are corresponding to $\mathrm{C}-\mathrm{O}$ (epoxy or alkoxy), and $\mathrm{C}=\mathrm{O}$ carboxylic acid, respectively that are suggest the complicate oxidation has been successful on Pristine carbon nanotube after chemical oxidation method [66].

\subsection{Hydrogen storage performance}

The hydrogen storage measurements were carried out at high pressure and room temperature. The sketch of hydrogen adsorption uptake for P-CNTs and F-CNTs are shown in figure 8. The result shows that hydrogen uptake in F-CNTs has higher storage capability to P-CNTs. The P-CNTs a slightly adsorbed low amount of hydrogen $0.65 \mathrm{wt} . \%$ at 80 bar pressure. However, hydrogen uptake capacity increased in F-CNTs i.e., $0.89 \mathrm{wt} \%$. at same pressure.

There are four possibilities for the reason for $\mathrm{H}_{2}$ uptake on the carbon nanotube: (1) Inside the carbon nanotubes, (2) surface of the carbon nanotubes, (3) Channel of carbon nanotubes and (4) Grove of carbon nanotubes. The way and adsorption sites of hydrogen in carbon nanotubes bundles are shown diagrammatically in figure 9 [67].

The increase $(\sim 37 \%)$ in $\mathrm{H}_{2}$ uptake capacity of F-CNTs as compared to the P-CNTs can therefore be attributed to the attachment of functional group on the surface as described in FTIR section in figure 7, which clues to rise the inter layer space in between the graphene layer, increase porosity, and generate more reactive surface sites on surface of F-CNTs for enhance of hydrogen adsorption. Our results correlate with a reported study of Patchkovskiiet al. [68] where the authors proposed that the hydrogen can be stored in 
between inter layers of graphene. They also investigated the hydrogen storage capacity of graphene layer bycomputations simulation, and displayed that the interlayer distance plays a key role on hydrogen storage capacity. Furthermore, Lee, S.Y et al. also reported that the chemically modified CNTs are having high storage density when compared to P-CNTs. This is due to the oxygen functional on their surface, which provides more hydrogen-related surface sites [69]. The strong acid treatment of P-CNTs followed by attachment of functional group can create the defects on surface that are match with Raman spectra in figure 6 which might be another region enhancement of hydrogen storage in F-CNTs. Some research groups where they had modified CNTs with chemical treatment and by varying temperatures and they found that the modified P-CNTs have high storage density to unmodified also identified the same behavior. The defect structure on surface may be considered as significant factor to enrich hydrogen storage in modified carbon nanotubes $[70,71]$. The appearing topological defect on the surface F-CNTs, which have been introduce hydrogen approachable active site by changing the characteristics of P-CNTs that offered the high attraction force for hydrogen molecules and carbon atom, which caused enhance the hydrogen storage density. As absorbed TEM image in figure $4(b, d)$ the defect on F-CNTs have been newly created and destructive surface morphology are forms after the acid treatment. It proposed that the enrich hydrogen storage in F-CNTs due to introduce the defect and open the end cap of CNTs, that are match with in TEM image figure 4(c). The simulation study shows the same finding and they have reported the introduction of the defects on surface can increase the local surface area, which can be, enhance the hydrogen storage density. The study suggests that graphene based derivative can be defect engineering to develop an effective storage media. [72-74]. Our results show that the 
engineering of the nanotubes surface and capped regions, nanotubes diameter, defect density, interlayer spacing and the surface functionalization group are effective in determination of the hydrogen storage capacity of the material.

\section{Conclusions}

In summary, the carbon nanotubes were functionalized using the chemical oxidation method. The hydrogen storage performance of P-CNTs and F-CNTs was determined at room temperature and high pressure using volumetric hydrogen storage system. The hydrogen uptake capacity for P-CNTs and F-CNTs at room temperature was measured to be 0.65 wt. $\%$ and 0.89 wt.\%, respectively. The result shows that this considerable $(\sim 37 \%)$ enhancement in the storage capacity of F-CNTs is due to occurrence of large number of oxygen functionalities and high defect density that provide more reactive surface sites for adsorption of hydrogen on the surface of F-CNTs. Thus, this single step modification of PCNTs in F-CNTs is an excellent option to enhance the hydrogen storage properties.

Acknowledgments-Authors are gratefully acknowledge the financial support received from Ministry of new and renewable energy(MNRE Grant No. 103/245/2015), New Delhi for providing financial assistance. 


\section{References:}

1. Rudolfa, P. et al., Hydrogen Storage in Graphene-Based Materials: Efforts towards Enhanced Hydrogen Absorption. ECS Journal of Solid State Science and Technology, 2013.2(10): pM3160-M3169.

2. Jain, I.P, Lal, C, Jain. A., Hydrogen storage in Mg: A most promising material. International Journal of Hydrogen Energy, 2010. 35(10):p.5133-5144.

3. Esswein, A.J., Nocera, D.G., Hydrogen production by molecular photocatalysis. Chem Rev, 2007. 107(10):p.4022-47.

4. Yurum. Y. T., Taralp, A., Veziroglu, T.N., Storage of hydrogen in nanostructured carbon materials. International Journal of Hydrogen Energy, 2009.34 (9):p.3784-3798.

5. 5.Ogden, J.M. et al., Developing an infrastructure for hydrogen vehicles: a Southern California case study. International Journal of Hydrogen Energy, 1999. 24(8):p.709-730.

6. Fichtner, M. et al., Nano technological aspects in materials for hydrogen storage. Advanced Engineering Materials, 2005.7(6):p.443-455.

7. Durbin, D.J., C. M.J., Review of hydrogen storage techniques for on board vehicle applications. International Journal of Hydrogen Energy, 2013.28(34):p.14595-14617.

8. Schlapbach, L., Zuttel, A., Hydrogen-storage materials for mobile applications. Nature, 2001. 414(6861):p.353-358.

9. Zhou, L., Zhou, Y.P., Sun.Y., Studies on the mechanism and capacity of hydrogen uptake by physisorption-based materials. International Journal of Hydrogen Energy, 2006. 31(2):p.259-264

10. Grochala, W., Edwards, P.P., Thermal decomposition of the non-interstitial hydrides for the storage and production of hydrogen. Chem Rev, 2004.104(3):p.1283-1316.

11. Dillon, A.C., et al., Storage of hydrogen in single-walled carbon nanotubes. Nature, 1997. 386(6623):p.377-379.

12. Liu, C., et al. Hydrogen storage in single-walled carbon nanotubes at room temperature, Science 1999; 286(5442):p.1127-1129.

13. Fan, Y.Y., et al. Hydrogen uptake in vapor-grown carbon nano fibers. Carbon, 1999. 37(10): p.1649-1652. 
14. Gupta, B.K, Srivastava, O.N., Further studies on microstructural characterization and hydrogenation behavior of graphitic nanofibres. International Journal of Hydrogen Energy, 2001.26(8):p.857-862.

15. Iijima, S. et al., Helical Microtubules of Graphitic Carbon. Nature, 1991.354(6348):p.5658.

16. Çelik B.,Erken E.,Eriş S.,Yıldız Y., Şahin B., Pamuk H., Sen F.,Highly monodisperse Pt (0)@AC NPs as highly efficient and reusable catalysts: the effect of the surfactant on their catalytic activities in room temperature dehydrocoupling of DMAB, Catalysis Sci Technol 6(6), p.1685-1692 (2016).

17. B. Sen, S. Kuzu, E. Demir,S. Akocak, F. Sen, Polymer-graphene hybride decorated Pt nanoparticles as highly efficient and reusable catalyst for the dehydrogenation of dimethylamine-borane at room temperature, International Journal of Hydrogen Energy, 42, 36,p. 23284-23291(2017).

18. B.Çelika,G.Başkayaa,H. Sertab, Ö. Karatepe, E. Erken, F.Şen,Monodisperse Pt(0)/DPA@GO nanoparticles as highly active catalysts for alcohol oxidation and dehydrogenation of DMAB, International Journal of Hydrogen Energy, Vo 41, 13, p. 5661-5669 (2016).

19. B.Çelik,S. Kuzu,E.Erken,H.Sert,Y.Koşkun,F.Şen, Nearly monodisperse carbon nanotube furnished nanocatalysts as highly efficient and reusable catalyst for dehydrocoupling of $D M A B$ and $C 1$ to $C 3$ alcohol oxidation, International Journal of Hydrogen Energy, 41, 4, p. 3093-3101(2016).

20. B. Sen, S.Kuzu, E.Demir, S. Akocak,F. Sen,Monodisperse palladium-nickel alloy nanoparticles assembled on graphene oxide with the high catalytic activity and reusability in the dehydrogenation of dimethylamine-borane, International Journal of Hydrogen Energy, 42, 36, p.23276-23283 (2017).

21. Y.Yıldı,,S.Kuzu,B.Sen,A. Savk,S. Akocak,F. Șen,Different ligand based monodispersed Pt nanoparticles decorated with rGO as highly active and reusable catalysts for the methanol oxidation, International Journal of Hydrogen Energy, 42, 18, p.13061-13069( 2017).

22. B.Sen,S. Kuzu,E. Demir, T. O. Okyay, F. Sen,Hydrogen liberation from the dehydrocoupling of dimethylamine-borane at room temperature by using novel and highly monodispersed RuPtNinanocatalysts decorated with graphene oxide, International Journal of Hydrogen Energy, 42, 36,p. 23299-23306 (2017). 
23. B. Sen, S.Kuzu, E. Demir, S. Akocak, F. Sen, Highly monodisperse RuCo nanoparticles decorated on functionalized multiwalled carbon nanotube with the highest observed catalytic activity in the dehydrogenation of dimethylamine-borane, International Journal of Hydrogen Energy, 42, 36, p.23292-23298(2017).

24. S. Akocak,B. Şen,N. Lolak, A. Şavk, M. Koca, S. Kuzu, F. Şen,One-pot three-component synthesis of 2-Amino-4H-Chromene derivatives by using monodisperse Pd nanomaterials anchored graphene oxide as highly efficient and recyclable catalyst, Nano-Structures \& Nano-Objects 11 p.25-31 (2017).

25. R. Ayranci,G. Baskaya'M. Guzel'S Bozkurt-M. Ak,A. Savk, F. Sen, Enhanced optical and electrical properties of PEDOT via nanostructured carbon materials: A comparative investigation, Nano-Structures \& Nano-Objects 11, p.13-19 (2017).

26. Darkrim, F., Levesque, D., Monte Carlo simulations of hydrogen adsorption in singlewalled carbon nanotubes. Journal of Chemical Physics, 1998.109(12):p.4981-4984.

27. Wang, Q.Y., Johnson, J.K., Molecular simulation of hydrogen adsorption in singlewalled carbon nanotubes and idealized carbon slit pores. Journal of Chemical Physics, 1999.110(1): p.577-586.

28. Cheng, J.R., et al. GCMC simulation of hydrogen physisorption on carbon nanotubes and nanotube arrays, Carbon, 2004. 42(10):p.2019-2024.

29. Cheng, H.M., Yang, Q.H., Liu, C., Hydrogen storage in carbon nanotubes. Carbon, 2001. 39(10):p.1447-1454.

30. Durgun,E., et al., Fictionalization of carbon-based nanostructures with light transition metal atoms for hydrogen storage. Physical review b, 2008 .77(8):p. 085405-08509.

31. Zuttel, A., et al., Hydrogen storage in carbon nanostructures. International Journal of Hydrogen Energy 2002; 27(2):p.203-212.

32. Poirier, E.,Chahine, R., Bose, T.K., Hydrogen adsorption in carbon nanostructures. International Journal of Hydrogen Energy, 2001. 26(8):p.831-835.

33. Wang, Q.K., et al. Hydrogen storage by carbon nanotube and their films under ambient pressure. International Journal of Hydrogen Energy, 2002. 27(5):p.497-500

34. Reddy, ALM, Ramaprabhu S., Hydrogen adsorption properties of single-walled carbon nanotube nano-crystalline platinum composites. International Journal of Hydrogen Energy, 2008; 33():p.1028-1034. 
35. Gayathri, V., Geetha, R., Hydrogen adsorption in defected carbon nanotubes Adsorption. Journal of the International Adsorption Society, 2007. 13(1): p.53-59.

36. Tylianakis, E., et al., Designing novel Nano porous architectures of carbon nanotubes for hydrogen storage. International Journal of Hydrogen Energy, 2014. 39(18):p.9825-9829.

37. Rajveer Singh Rajaura, Subodh Srivastava, Vinay Sharma,PK Sharma and YK Vijay Synthesis of Graphene Oxide/Polyaniline Composites for Hydrogen Storage, Advanced Science, Engineering and Medicine,9, 1-7(2017)

38. R. S. Rajaura, S. Srivastava, V. Sharma, P.K. Sharma, C. Lal, M. Singh, H.S. Palsania, Y.K. Vijay, Role of interlayer spacing and functional group on the hydrogen storage properties of graphene oxide and reduced graphene oxide, International journal of hydrogen energy, 41, 9454-9461(2016) .

39. 1.E.Durgun,S.Ciraci, and T. Yildirim, Fictionalization of carbon-based nanostructures with light transition-metal atoms for hydrogen storage. Physical review b 77, 085405-8, 2008 .

40. S. H Aboutalebi, S.A.Yamini, I. Nevirkovets, K. Konstantinov, and H. K. Liu . Enhanced Hydrogen Storage in Graphene Oxide-MWCNTs Composite at Room Temperature. Advanced Energy Materials 2 (12), 1439-1446 (2012).

41. G. Srinivas , Y. Zhu , R. Piner , N. Skipper , M. Ellerby , R. Ruoff. Synthesis of graphene-like nanosheets and their hydrogen adsorption capacity. Carbon, 48, 3, p. 630635 (2010).

42. B.H. Kim, W. G. Hong, H. Y. Yu, Y.K. Han, S. M. Lee, S. J. Chang, H. R. Moon, Y. Jun and H.J. Kim . Thermally modulated multilayered graphene oxide for hydrogen storage.Physical Chemistry Chemical Physics 14 (4), 1480-1484 (2012).

43. G. Gundiah, A. Govindaraj, N. Rajalakshmi, K. S. Dhathathreyan and C. N. R. Rao., Hydrogen storage in carbon nanotubes and related materials. Journal of Materials Chemistry, 2, 2003. 
44. . C. Liu, Y. Chen, C.Z. Wu, S.T. Xu, H.M. Cheng. Hydrogen storage in carbon nanotubes revisited 48, 2, p. $452-455$ (2010).

45. S. Orimo and G. Majer, Hydrogen in the mechanically prepared nanostructure graphite. Appl. Phys. Lett. 75, 3093 (1999).

46. V. B. Parambhath, R. Nagar, and S. Ramaprabhu ,Effect of Nitrogen Doping on Hydrogen Storage Capacity of Palladium Decorated Graphene. Langmuir, 28, p.7826-7833 (2012).

47. M.S.Leo Hudson, H. Raghubanshi, S. AwasthiT.Sadhasivam,A. Bhatnager, S.Simizu, S.G.SankarO.N.Srivastava. Hydrogen uptake of reduced graphene oxide and graphene sheets decorated with Fe nanoclusters. International journal of hydrogen energy 39, 16, p.8311-8320 (2014).

48. P. Chen, X. Wu, J. Lin, K. L. Tan. High $\mathrm{H}_{2}$ Uptake by Alkali-Doped Carbon Nanotubes under Ambient Pressure and Moderate Temperatures. Science, 285, 5424, p.91-93 (1999).

49. G. Mpourmpakis , G. E. Froudakis . SiC Nanotubes: A Novel Material for Hydrogen Storage. Nano Lett.6 , 8 , p. 1581-1583 (2006).

50. A. Chambers,C. Park, R. Terry K. Baker, and N. M. Rodriguez, Hydrogen Storage in Graphite Nanofibers ., J. Phys. Chem. B, 102 (22), pp 4253-4256 (1998).

51. Geng, H.Z. Et al, Hydrogen storage in microwave-treated multi-walled carbon nanotubes. International Journal of Hydrogen Energy, 2010. 35(5): 2073-2082.

52. Wu HM, Wexler D, Ranjbartoreh AR, Liu HK, Wang GX. Chemical processing of double-walled carbon nanotubes for enhanced hydrogen storage. International Journal of Hydrogen Energy, 2010.3590(12): p.6345-6349.

53. Liu, X., et al, Preparation of multiwalled carbon nanotubes/Cd0.8Zn0.2S nanocomposite and its photo catalytic hydrogen production under visible-light.International Journal of Hydrogen Energy 2012. 37(2):p.1375-1385.

54. Datsyuk, V., et al., Chemical oxidation of multiwall carbon nanotubes. Carbon, 2008. 46(6): p.833-840. 
55. Lachawiec, A.J., T.R. DiRaimondo, and R.T. Yang, A robust volumetric apparatus and method for measuring high-pressure hydrogen storage properties of nanostructured materials. Review ofScientific Instruments, 2008. 79(6):p. 063906.

56. Rakhia, R.B., Sethupathib, B.K., Ramaprabhu, S.et al., Synthesis and hydrogen storage properties of carbon nanotubes. International Journal of Hydrogen Energy, 2008. 33(1):p.38-386.

57. Rather, S.U., Zacharia, R., Surface adsorption and microspore filling of the hydrogen in activated MWCNTs. International Journal of Hydrogen Energy. 2008, 33(22):p.67106718 .

58. Kocabas, S., Kopac, T., Dogu, G., Dogu, T., Effect of thermal treatments and palladium loading on hydrogen sorption characteristics of single-walled carbon nanotubes. International Journal of Hydrogen Energy, 2008.33(6):p.1693-1699.

59. JinKim, S., Park, Y.J., Defect-induced loading of Pt nanoparticles on carbon nanotubes. Applied physics letters, 2007.90:p.023114-023117.

60. Sharma, V., Rajaura, R. S., Purohit, S., Patidar, D., Sharma, K., Cost Effective Synthesis of Carbon Nanotubes and Evaluation of their Antibacterial Activity. Nano Trends: A Journal of Nanotechnology and Its Applications, 2014 .22(1):p.8-12.

61. Chiang, Y.C., W.H. Lin, and Y.C. Chang, The influence of treatment duration on multiwalled Carbon nanotubes functionalized by H2SO4/HNO3 oxidation. Applied Surface Science, 2011.257(6): p.2401-2410.

62. Dresselhaus, M.S., Dresselhaus, G., Hofmann, M.,The big picture of Raman scattering in carbon nanotubes. Vibrational Spectroscopy, 2007.45(2):p.71-81.

63. Brown, S.D.M, Jorio A., Dresselhaus, M.S., Dresselhaus, G., Observations of the D-band feature in the Raman spectra of carbon nanotubes. Physical Review B, 2001.64(7):p.073403.

64. Ferrari, A.C., Robertson, J., Interpretation of Raman spectra of disordered and amorphous carbon. Physical ReviewB, 2000. 61(20):p.14095-14107.

65. Cançado,L. G.,Quantifying Defects in Graphene via Raman Spectroscopy at Different Excitation Energies, Nano latter,2011. 11(8):p.3190-3196.

66. Chiang, Y.C., Lin, W.H, Chang, Y.C.,The influence of treatment duration on multiwalled carbon nanotubes functionalized by $\mathrm{H}_{2} \mathrm{SO}_{4} / \mathrm{HNO}_{3}$ oxidation. Applied Surface Science, 2011; 257(6):p.2401-2410. 
67. Kim, YJ, et al, Electrical conductivity of chemically modified multiwall carbon nanotube/epoxy composites. Carbon 2005; 43(1): 23-30.

68. Patchkovskii, S., et al., Graphene nanostructures as tunable storage media for molecular Hydrogen. Proceedings of the National Academy of sciences, 2005.102, (30):p.1043910444.

69. Lee, S.Y., et al., Hydrogen Adsorption of Acid-treated Multi-walled Carbon Nanotubes atLow Temperature. Bulletin of the Korean chemical society, 2010.31(6):p.1596-1600.

70. Soo-Jin Park et al., Effect of temperature on activated carbon nanotubes for hydrogen storage behaviors. International Journal of Hydrogen Energy.2010.35 ():p. 6757 -6762.

71. Chena,C.H.,etal.,Hydrogen storage by KOH-modified multi-walled carbon nanotubes.International Journal of Hydrogen Energy, 2007.32 ():p237-246.

72. P. K Sharma, V. Sharma, R. S. Rajaura, S. Srivastava, S.S Sharma, M. Singh, Y.K., Vijay, SHI induced defects in chemically synthesized graphene oxide for hydrogen storage applications. AIP Conference Proceedings, 1728, 1, 020531(2016).

73. Yadav, S., et al., Defect engineering of graphene for effective hydrogen storage. International journal of hydrogen e energy 2014. 39(10):p.4981-4995.

74. Lugo,G., MP2 Study of Physisorption of Molecular Hydrogen onto Defective Nanotubes: Cooperative Effect in Stone-Wales Defects. J. Phys. Chem. 2016, 120 (27), pp 49514960. 


\section{Table Caption}

Table 1 Summary of hydrogen storage studies of various carbon nanostructure materials.

\section{Figure Caption:}

Figure 1 Overall Synthesis procedure of F-CNTs.

Figure 2 Schematic diagram of volumetric hydrogen storage system.

Figure 3 SEM images of P-CNTs (b) and F-CNTs(c). Image (b) is showing the highly agglomeration interconnected fiber. Image (c) is showing the morphology of F-CNTs was disturbed after acid treatment.

Figure 4 Bright field TEM images of P-CNTs ( $a$ and its insert) and image (b-f) is F-CNTs. Scale bar of figure (a) insert is $50 \mathrm{~nm}$. In image (b), black arrow indicate the side wall of FCNTs has been damage and image (c) is showing the open the end cap of F-CNTs Image (d) showing defect on surface and white arrow line in image (e) is showing the edge of graphene. Image (f) is showing edge of graphene layer is partially destroyed.

Figure 5 XRD patterns of P-CNTs and F-CNTs.

Figure 6 Raman spectra of P-CNTs and F-CNTs.

Figure 7 FTIR spectra of P-CNTs and F-CNTs.

Figure 8 Hydrogen uptakes by P-CNTs and F-CNT at 80 bars.

Figure 9 different storage sites of carbon nanotubes. 
Table 1

\begin{tabular}{|c|c|c|c|c|c|}
\hline Structured & $\begin{array}{c}\text { Binding } \\
\text { Energy } \\
\mathrm{E}_{\mathrm{b}}\left(\mathrm{H}_{2}\right)\end{array}$ & $\begin{array}{c}\text { Condition } \\
\text { (Temperature } \\
\text { and Pressure) }\end{array}$ & Wt \% & $\begin{array}{c}\text { Desorption } \\
\text { Temperature } \\
\qquad\left(\mathrm{T}_{\mathrm{D}}\right)\end{array}$ & Reference \\
\hline Carbon nanofiber & - & $\begin{array}{c}295 \mathrm{~K}, 105 \\
\text { bar }\end{array}$ & 0.7 & - & 32 \\
\hline CNT thin film & - & $\begin{array}{c}\text { Room } \\
\text { temperature, } \\
\text { Ambient } \\
\text { pressure }\end{array}$ & 8 & - & 33 \\
\hline $\begin{array}{l}\text { CNT based three } \\
\text { dimensional diamond } \\
\text { like architecture }\end{array}$ & - & $\begin{array}{c}\text { Room } \\
\text { temperature }\end{array}$ & 8 & - & 36 \\
\hline $\begin{array}{l}\text { Sc-functionalized } \\
\text { Graphene }\end{array}$ & 0.17 & - & 8.0 & $391 \mathrm{~K}$ & 39 \\
\hline $\begin{array}{l}\text { Sc- functionalized } \\
\text { SWCNT }\end{array}$ & 0.47 & - & $8.0-9.8$ & $733 \mathrm{~K}$ & 39 \\
\hline $\begin{array}{l}\text { V-Graphene } \\
\text { functionalize }\end{array}$ & 0.32 & - & 7.5 & $570 \mathrm{~K}$ & 39 \\
\hline $\begin{array}{l}\text { V- functionalized } \\
\text { SWCNT }\end{array}$ & 0.46 & - & 9.2 & $672 \mathrm{~K}$ & 39 \\
\hline $\begin{array}{l}\text { Ti-functionalized } \\
\text { Graphene }\end{array}$ & 0.35 & - & 7.8 & $611 \mathrm{~K}$ & 39 \\
\hline $\begin{array}{l}\text { Ti- functionalized } \\
\text { SWCNT }\end{array}$ & 0.56 & - & $5.3-7.8$ & $867 \mathrm{~K}$ & 39 \\
\hline $\begin{array}{l}\text { Graphene Oxide- } \\
\text { Multiwall Carbon } \\
\text { Nanotube }\end{array}$ & - & $\begin{array}{l}298 \mathrm{~K}, 50 \\
\text { bar }\end{array}$ & & - & 40 \\
\hline $\begin{array}{l}\text { Reduced Graphene } \\
\text { Oxide Multiwalled } \\
\text { Carbon Nanotube }\end{array}$ & - & $\begin{array}{l}298 \mathrm{~K}, 50 \\
\text { bar }\end{array}$ & 2.1 & - & 40 \\
\hline $\begin{array}{c}\text { Graphene like } \\
\text { nanomaterils }\end{array}$ & & $\begin{array}{l}298 \mathrm{~K}, 10 \\
\text { bar }\end{array}$ & 1.2 & & 41 \\
\hline $\begin{array}{l}\text { Thermally modulated } \\
\text { multilayered graphene } \\
\text { oxide }\end{array}$ & - & $\begin{array}{l}298 \mathrm{~K}, 90 \\
\text { bar }\end{array}$ & 0.5 & - & 42 \\
\hline $\begin{array}{l}\text { Acid treated carbon } \\
\text { nanotube }\end{array}$ & - & $\begin{array}{c}300 \mathrm{~K}, 143 \\
\text { bar }\end{array}$ & 3.7 & - & 43 \\
\hline Air-oxidized MWCNTs & - & $\begin{array}{c}20.1 \mathrm{~K}, 125 \\
\text { bar }\end{array}$ & 0.9 & - & 44 \\
\hline CO2-oxidized MWCNT & - & $\begin{array}{c}20.1 \mathrm{~K}, 125 \\
\text { bar }\end{array}$ & 1 & - & 44 \\
\hline
\end{tabular}




\begin{tabular}{|c|c|c|c|c|c|}
\hline $\begin{array}{l}\text { KOH-activated } \\
\text { MWCNTs }\end{array}$ & - & $\begin{array}{l}19.9 \mathrm{~K} \\
120 \mathrm{bar}\end{array}$ & 0.156 & - & 44 \\
\hline $\begin{array}{c}\text { Nano-structured } \\
\text { graphite }\end{array}$ & - & $\begin{array}{c}300 \mathrm{~K}, 10 \\
\text { bar }\end{array}$ & 7.4 & & 45 \\
\hline $\begin{array}{l}\text { Pd decorated nitrogen } \\
\text { doped graphene }\end{array}$ & & $\begin{array}{l}298 \mathrm{~K}, 40 \\
\text { bar }\end{array}$ & 4.4 & & 46 \\
\hline Pd decorated graphene & & $\begin{array}{l}298 \mathrm{~K}, 40 \\
\text { bar }\end{array}$ & 1.47 & & 46 \\
\hline $\begin{array}{l}\text { Nitrogen doped } \\
\text { graphene }\end{array}$ & & $\begin{array}{l}298 \mathrm{~K}, 40 \\
\text { bar }\end{array}$ & 0.81 & & 46 \\
\hline Graphene oxide & & $\begin{array}{c}300 \mathrm{~K}, 50 \\
\text { bar }\end{array}$ & 0.17 & & 47 \\
\hline $\begin{array}{l}\text { Thermaly reduced } \\
\text { graphene oxide }\end{array}$ & & $\begin{array}{l}300 \mathrm{~K}, 50 \\
\text { bar }\end{array}$ & 0.32 & & 47 \\
\hline $\begin{array}{l}\text { Chemically reduced } \\
\text { graphene oxide }\end{array}$ & & $\begin{array}{c}300 \mathrm{~K} \\
50 \mathrm{bar}\end{array}$ & 1 & & 47 \\
\hline $\begin{array}{l}\text { Fe decorated Graphene } \\
\text { nanosheets }\end{array}$ & & $77 \mathrm{~K}, 50 \mathrm{bar}$ & & & 47 \\
\hline Li doped MWNT & - & $\begin{array}{c}200-400 \mathrm{~K} \\
1 \mathrm{bar}\end{array}$ & 20 & - & 48 \\
\hline K doped MWNT & - & $\begin{array}{l}200-400 \mathrm{~K}, \\
1 \mathrm{bar}\end{array}$ & 14 & - & 48 \\
\hline $\begin{array}{l}\text { Silicon-carbon } \\
\text { nanotubes }\end{array}$ & - & $\begin{array}{l}175 \mathrm{~K} \\
100 \mathrm{bar}\end{array}$ & 3.68 & - & 49 \\
\hline
\end{tabular}


Figure 1

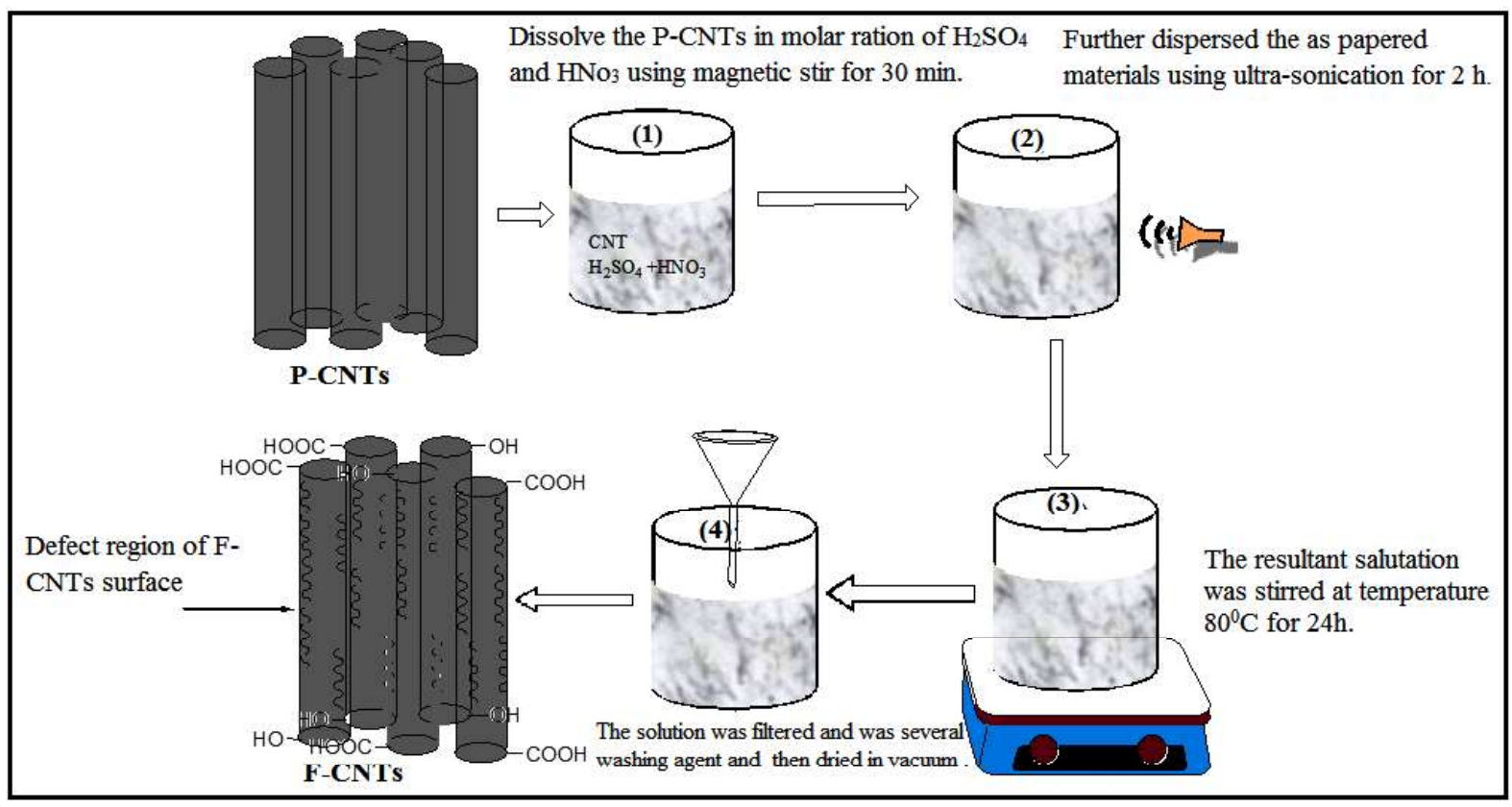


Figure 2

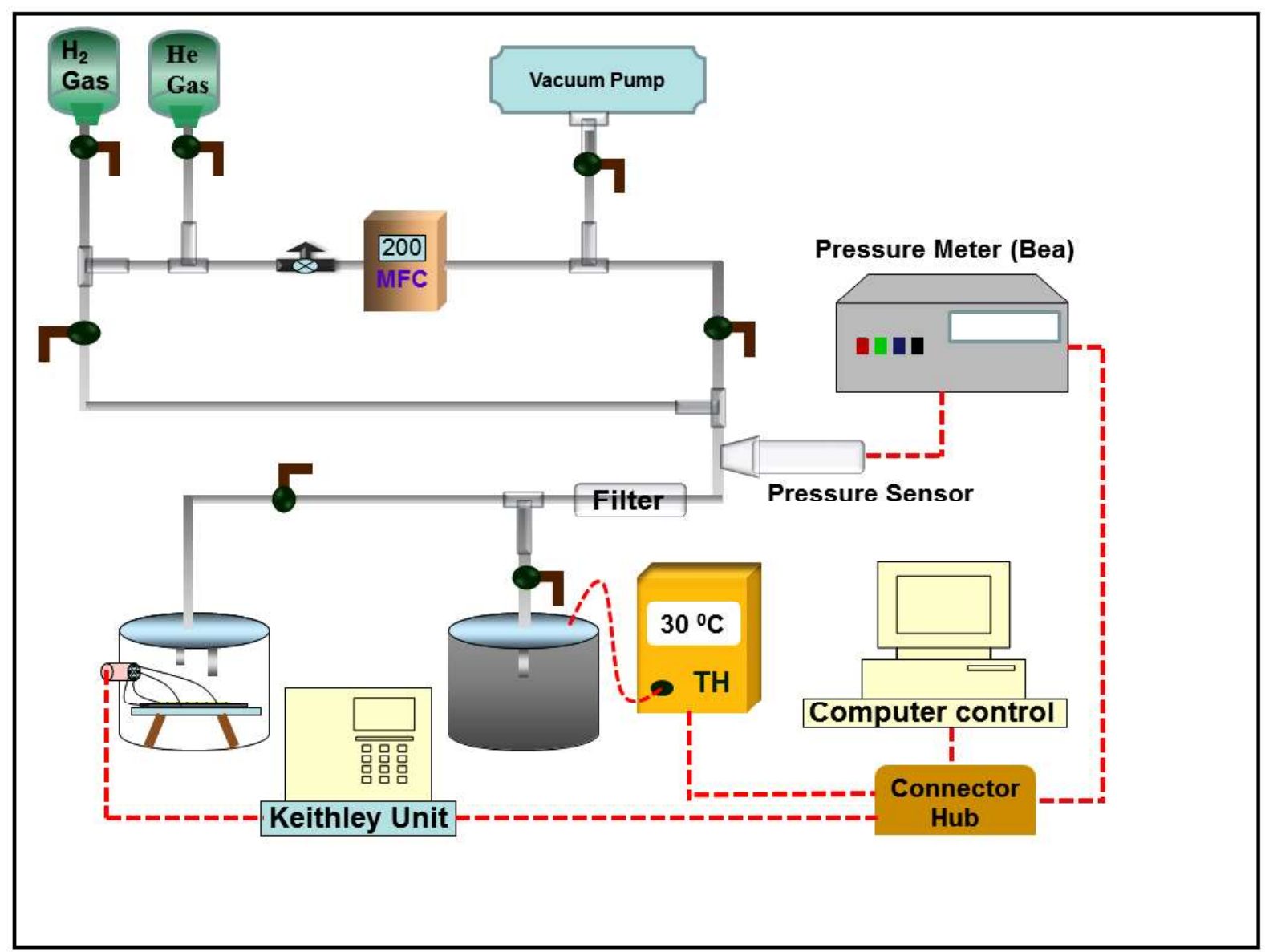


Figure 3
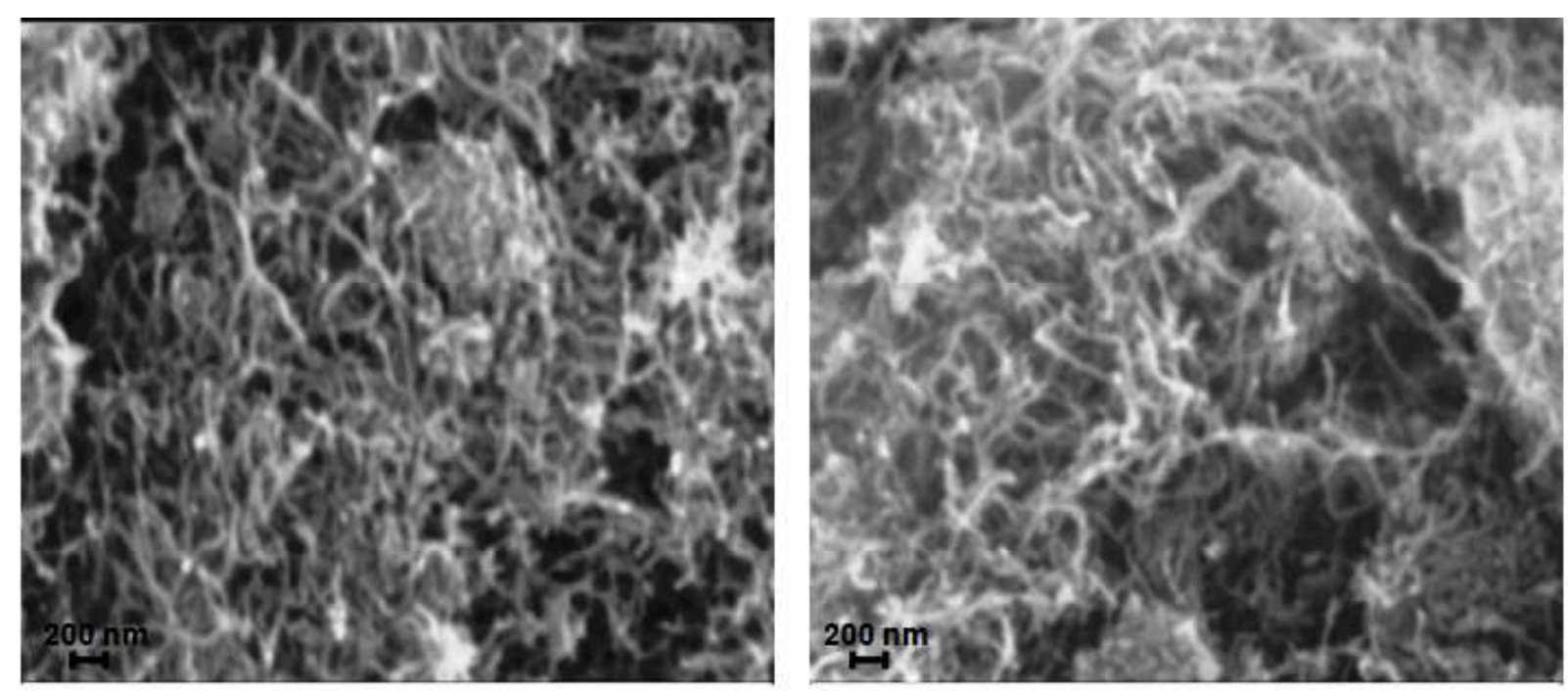
Figure-4
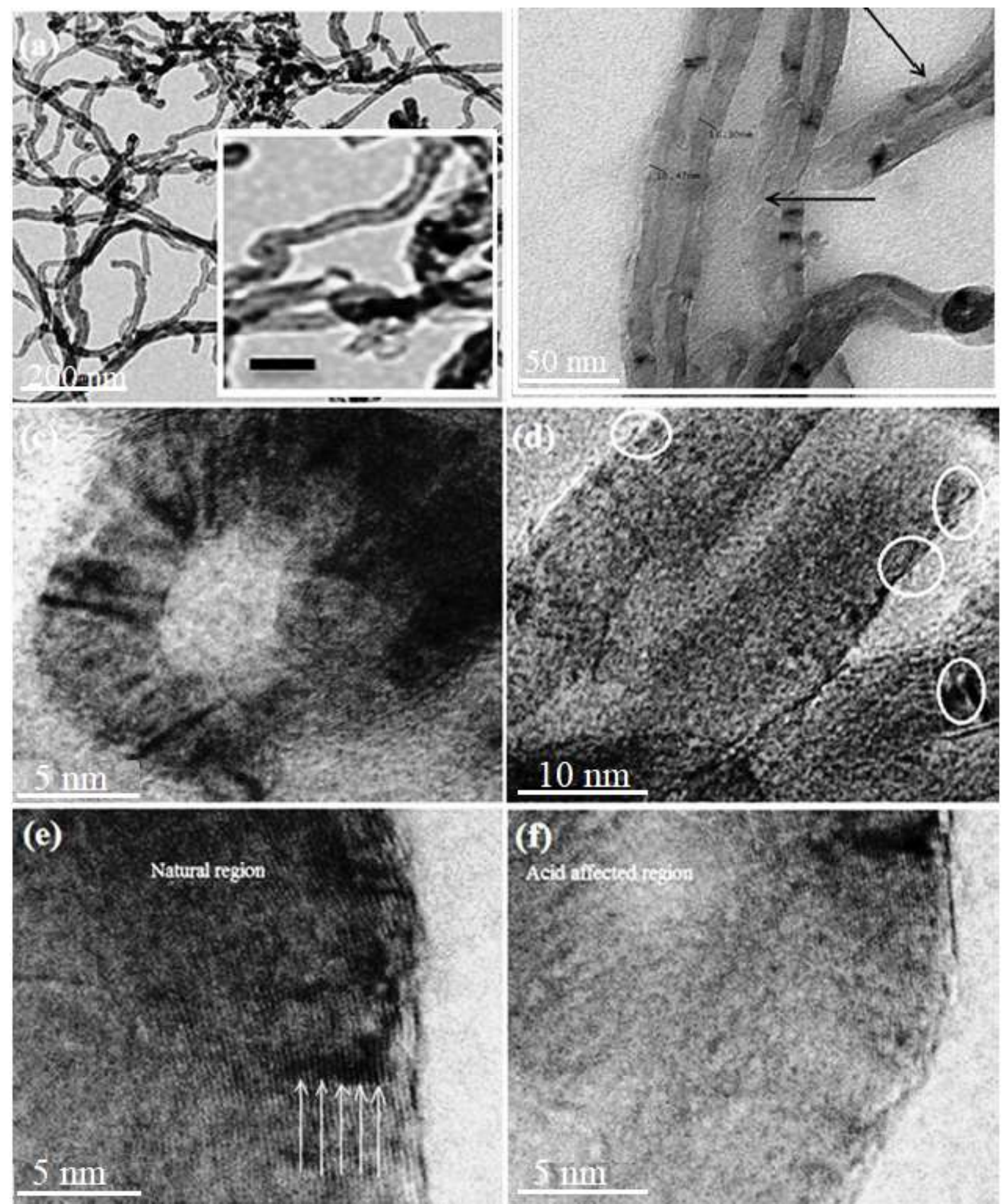
Figure 5

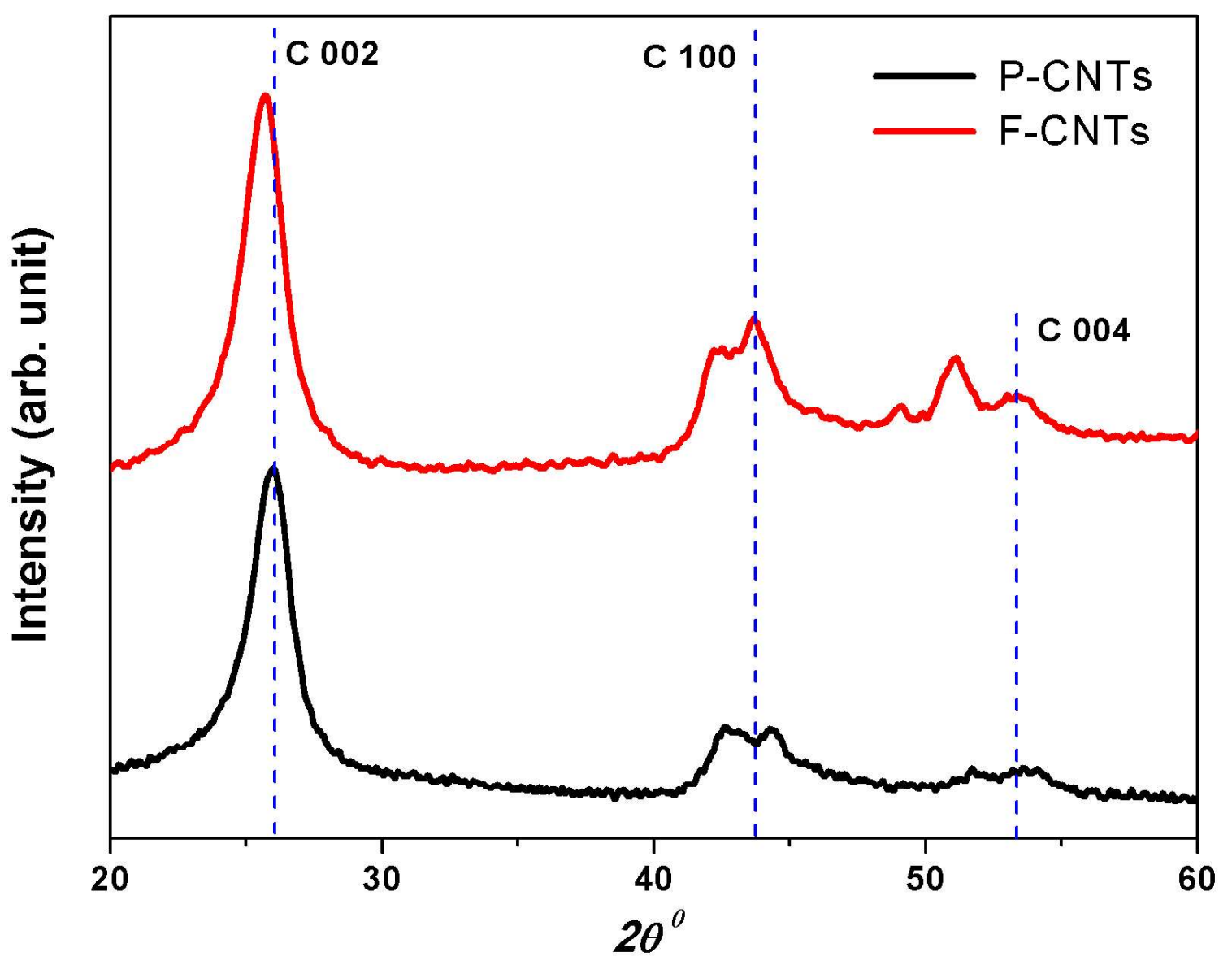


Figure 6

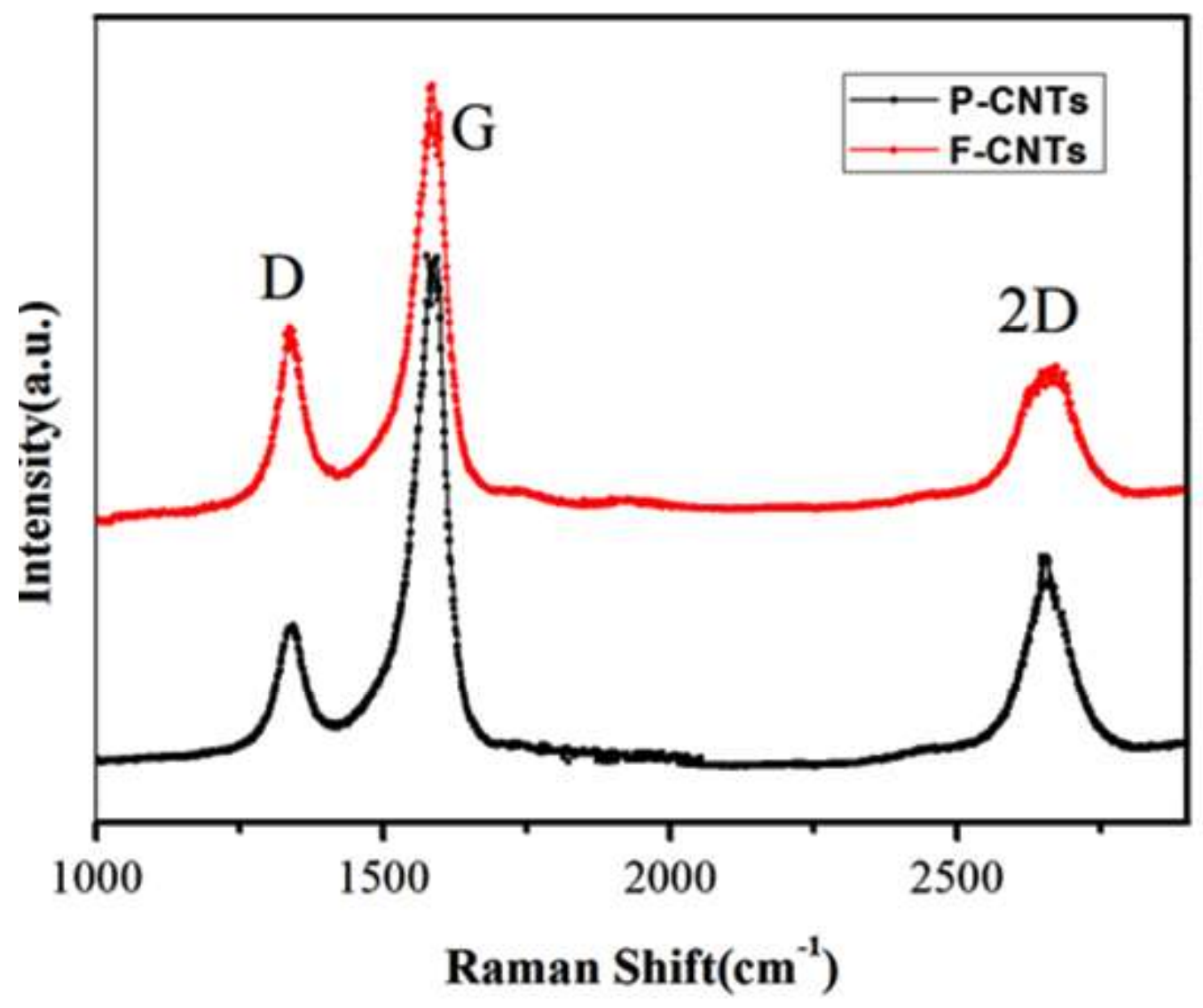


Figure 7

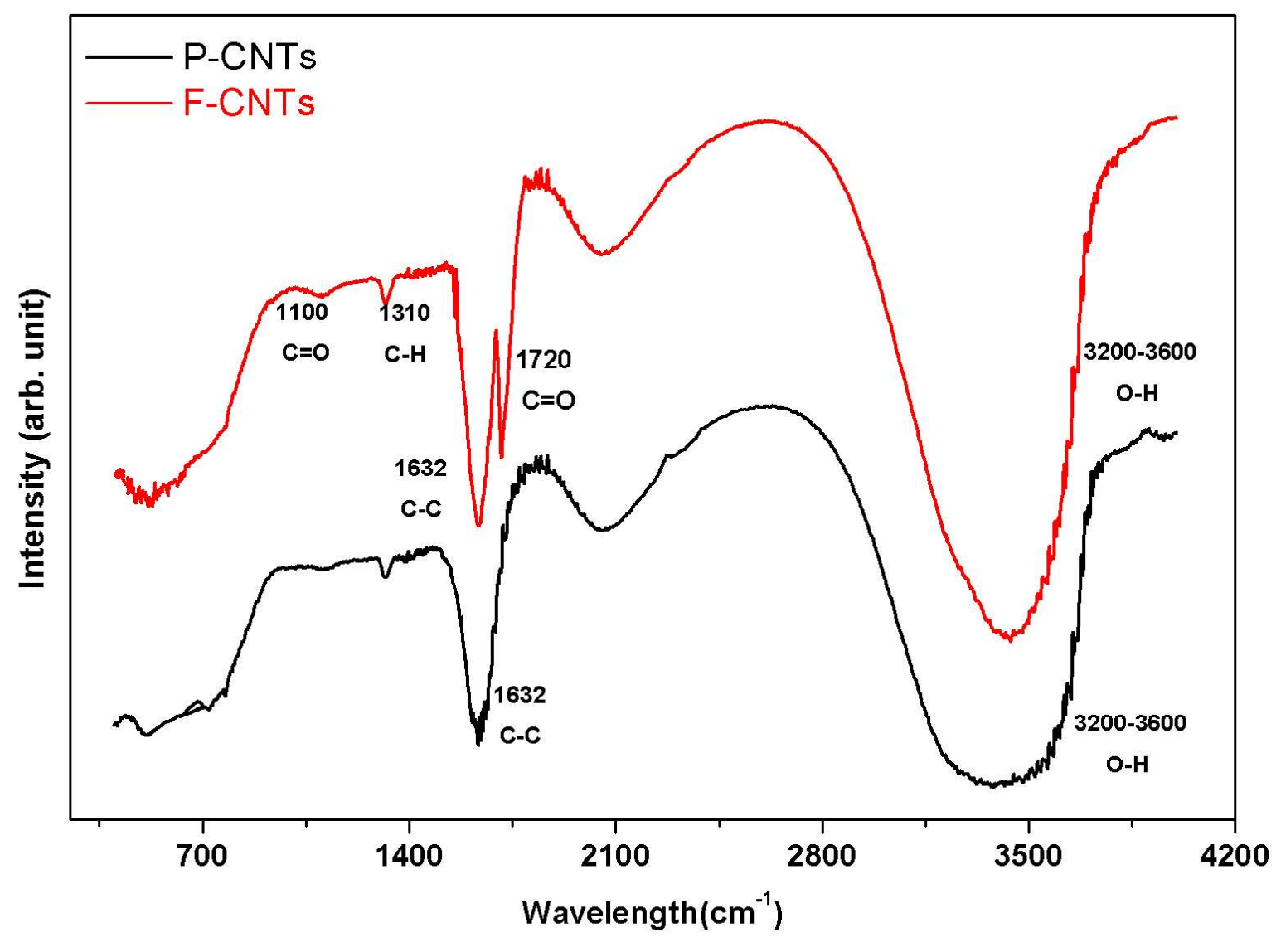


Figure 8

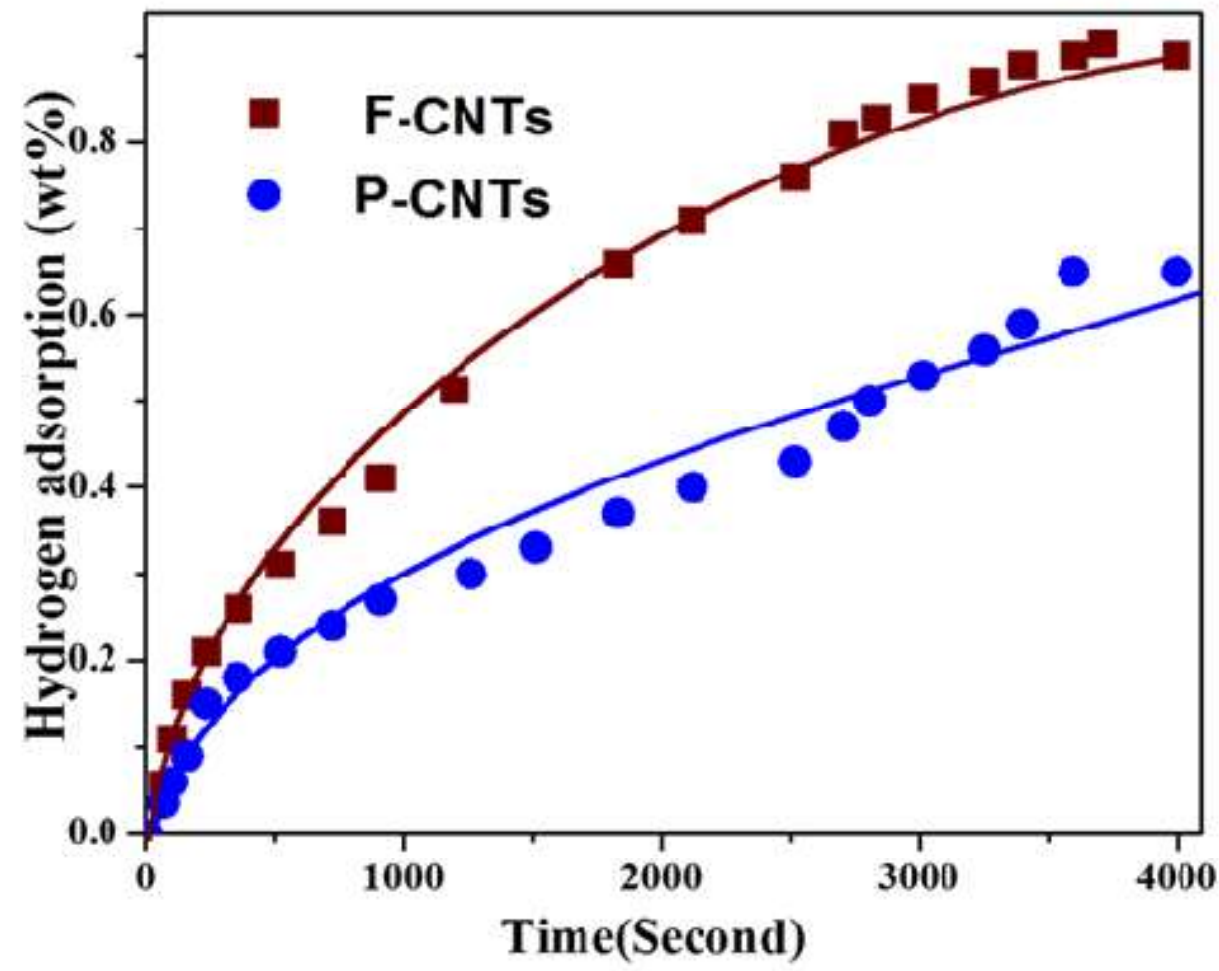


Figure 9

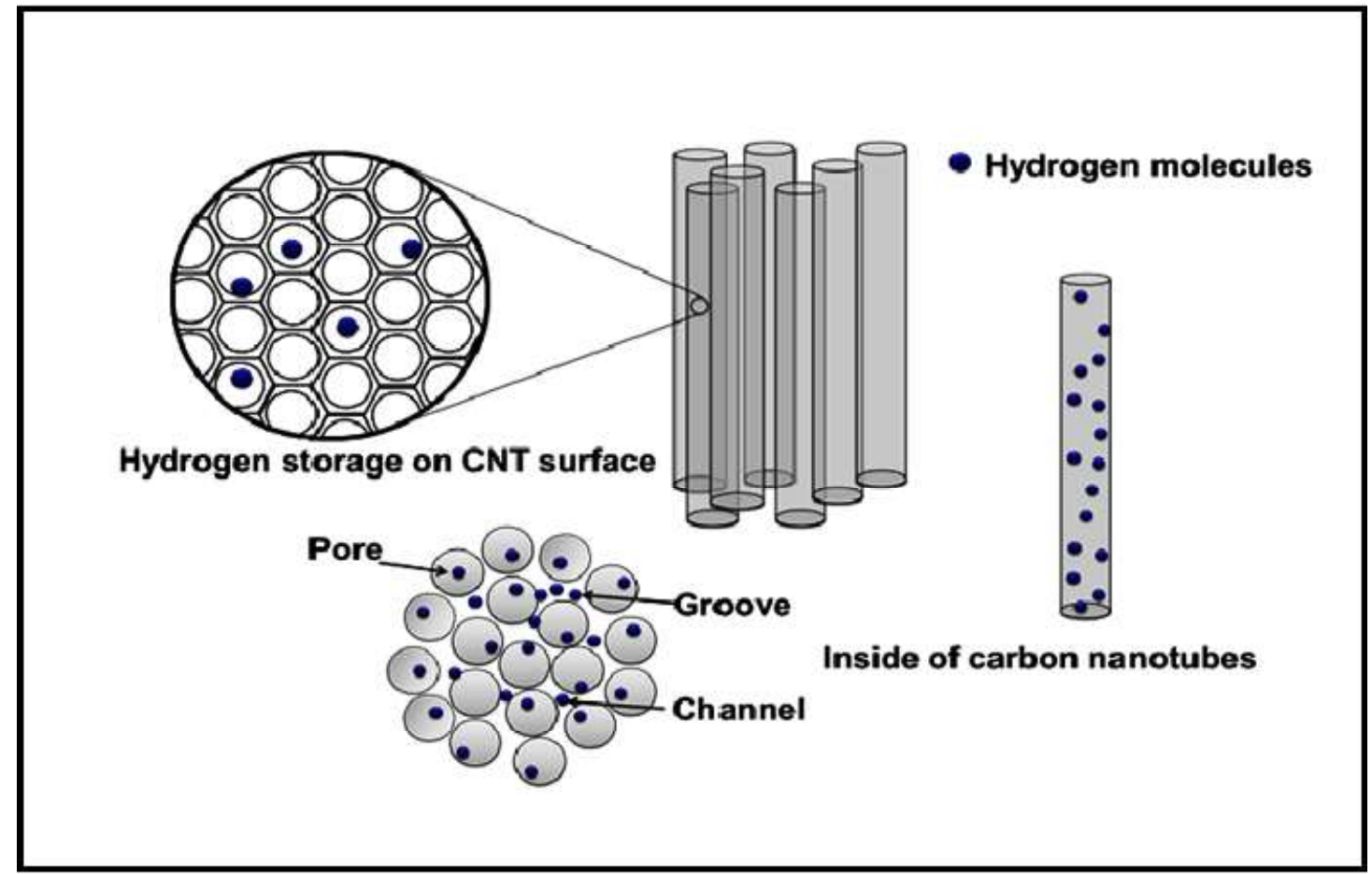

